\title{
Factors affecting TB case detection and treatment in the Sissala East District, Ghana*
}

\author{
Collins K. Ahorlu" ${ }^{1 \#}$, Frank Bonsu ${ }^{2}$ \\ ${ }^{1}$ Noguchi Memorial Institute for Medical Research, University of Ghana, Legon, Ghana; \\ \#Corresponding Author: cahorlu@noguchi.mimcom.org \\ ${ }^{2}$ National TB Control Programme, Ghana Health Service, Accra, Ghana fabonsu@gmail.com
}

Received 16 July 2013; revised 24 August 2013; accepted 10 September 2013

Copyright (C) 2013 Collins K. Ahorlu, Frank Bonsu. This is an open access article distributed under the Creative Commons Attribution License, which permits unrestricted use, distribution, and reproduction in any medium, provided the original work is properly cited.

\section{ABSTRACT}

Background: Tuberculosis remains a major health problem affecting about a third of the world population despite a number of preventive and control measures taken in the past few decades. Eighty-five percent of all tuberculosis cases are concentrated in Asia and Africa due to lack of education and health care infrastructure. Objective: To determine factors affecting low tuberculosis case detection in the Sissala East district in the Upper West Region of Ghana. Methods: This was a descriptive study where semistructured questionnaire was administered to 61 respondents; six focus group discussions and 20 in-depth interviews were conducted to generate both qualitative and quantitative data for analysis. Results: Tuberculosis, known locally as Kesibine was identified as a major problem in the district. The two most frequently reported TB related distresses were coughing (96.7\%) and chest pains (95.0\%). However, these distresses were reported more after probing for them. The most frequently spontaneously reported distress was reduced income $(60.7 \%)$ for patients. The most prominent cause reported was sexual pollution $(72.2 \%)$. Suspected tuberculosis patients are stigmatized and are denied sex by their partners as shown in the following narrative; I will not eat or have sex with her or eat any leftover from her plate (male local healer, In-depth interview). Case detection and treatment is hampered by lack of communication between sub-district facilities and the district hospital to aid laboratory diagnosis. Conclusion: There is therefore the need for vigorous health education

${ }^{*}$ Competing Interest: We declare that we have no competing interest in writing this paper. to inform the people about the biomedical causes of TB and the availability of appropriate treatment for the disease at health facilities. However, the education should not aim at changing the "wrong beliefs" but focus on making people aware of the biomedical causes and see TB as treatable infection, which could be controlled.

Keywords: TB; Treatment; Case Detection; Ghana

\section{INTRODUCTION}

Tuberculosis (TB) remains a major health problem affecting about a third of the world population despite a number of preventive and control measures taken in the past few decades. It is responsible for an estimated 8.8 million cases and 1.4 million deaths globally [1,2]. Eighty-five percent of these TB cases are concentrated in Asia and Africa where there is a lack of education, health care infrastructure, poverty and overcrowding [1-5].

It is estimated that Africa contributes about $29 \%$ and $34 \%$ of all TB related morbidity and mortality to the global burden. In Ghana, TB remains a major cause of preventable adult morbidity and mortality [6-11] and in 2007, WHO has estimated that 50,000 new TB cases occurred in Ghana, making it the $19^{\text {th }}$ most TB burden country in Africa. However, TB has remained a fearful disease among the Ghanaian population as demonstrated by the local Akan name for it- "Nsamanwa", which connotes both fear and death. The term "Nsamanwa" literally means "ghost cough", which suggests that once you get the disease, you have literally become a ghost or a dead person [7-11]. The linguistic difference between the Akan speaking and the Sissala speaking people notwithstanding, TB patients are generally stigmatized across the globe [10-12]. With this seriousness and fear associated to TB, it is expected that suspected cases will seek for 
treatment early at the health facility. But this was not the case in the Sissala East District in the Upper West district of Ghana where virtually no TB cases were being diagnosed. This could be due to massive stigma associated with the disease among other things [6-16].

The main strategy for TB treatment globally is the directly observed treatment short course (DOTS) which relies on case detection and treatment with multiple antimicrobial drugs for at least six months. It is anticipated that this strategy will enhance treatment compliance and thereby improve treatment outcome. Central to this strategy however is laboratory diagnosis to confirm clinical cases before treatment is initiated $[1,5,7,12]$. This is where the attitude of health workers toward patients in terms of stigmatization could negatively influence the health seeking behaviour among suspected patients [10, 11,17-20].

Social factors that are known to be driving the global increase in TB cases include; overcrowding, especially in urban centres, late reporting and diagnosis, non-compliance to treatment schedule, lack of commitment on the part of national control programme in developing countries, lack of education, health care infrastructure and poverty $[2,3,6]$.

Despite increased efforts at prevention and the widespread availability of effective short-course anti-tuberculosis chemotherapy in the past few decades, the incidence of tuberculosis is on the increase both in developed and developing countries. The emergence of extremely drug resistant tuberculosis (XDR-TB) from South Africa is going to be a major threat to TB control in Africa (http://allafrica.com/stories/200610180119.html). This is because, in sub-Saharan Africa, case detection rates are still low and the period from first symptom to diagnosis and treatment could be quite long [21].

This study was designed to determine factors affecting low TB case detection in the Sissala East District in the Upper West Region of Ghana. This operational study became necessary to generate information for the Ghana national TB control programme for appropriate remedial actions to be taken to forestall any catastrophe that may result from untreated TB cases in the study area.

\section{MATERIALS AND METHODS}

\subsection{Study Area}

The study was conducted in the Sissala East, a rural district located in the north-eastern part of the Upper West Region of Ghana with Tumu as its capital. The district shares about 300 kilometer border with Burkina Faso. According to the 2010 population and housing census, there are 56,528 people living in the district [22]. The district is predominantly rural where over $75 \%$ of the people are engaged in subsistence agriculture (DHMT annual report, 2010). The formal health system in the district consists of 1 district hospital, 5 health centers (HC). However, low health service utilization was reported in the district (DHMT, annual report, 2010). The national TB control program initiated this research to ascertain why very little or no TB cases were being recorded in the district in recent years.

\subsection{Data Collection Techniques}

This was a descriptive study employing both qualitative and quantitative techniques for data collection. EMIC (insider perspective) interviews were conducted with 61 persons to generate quantitative data. EMIC interviews are instruments used for assessing representations of illness or specified health problems from the perspective of affected persons, their family or community members. The instrument blends qualitative and quantitative approaches to study illness-related experiences, meanings and behaviours [23]. The EMIC tool was designed to generate relevant representations and categories of distress, perceived causes, help-seeking behaviours and perceived or experienced TB related stigma. Respondents were enrolled into the study through purposive sampling, using the snowball technique, where each person identified also brought at least one other person with similar condition. An initial screening was done on each person brought to be sure that they meet the inclusion criterion, which is coughing continuously for 14 days or more before they were enrolled into the study after receiving their consent to participate. This technique was adopted we could not generate a list of suspected TB cases and the district hospital has no recent patients list to select the sample from. However, community leaders were able to refer some suspected cases to the researchers who were then asked to refer at least one person with similar condition (coughing for 14 or more days).

To allow for group interactions and to generate divergent locally valid TB representations and categories, Six FGDs (three for each sex) were conducted with selected adults aged 18 years and above. Also, 20 in-depth interviews were conducted (three chiefs, three queen mothers or women representatives, six health workers and eight traditional healers). These qualitative techniques allowed us to determine the ethnographic features of TB in the district.

\subsection{Analysis}

Qualitative data were analysed using Maxqda software after the data were entered into Microsoft word in a format that allows importation to Maxqda in a preformatted 
coded form. Content analysis was then performed on relevant segments to generate representative narratives for presentation to complement and clarify quantitative findings. The quantitative data was entered into EpiInfo version 3.3.2, which was also used to perform descriptive analysis for presentation.

\subsection{Ethical Considerations}

The study was reviewed by the Institutional Review Board of the Noguchi Memorial Institute for Medical Research, University of Ghana. Each participant was informed of the objectives, methods, anticipated benefits and potential hazards of the study. Participants were assured that all information collected for the study would be kept confidential, and that in any resulting publication it would not be possible to link the data to individuals and families in the study. Written inform consent was obtained from all participants and none have declined participation in the study. Participants signed/thump print the consent form together with a witness to accept participation in the study.

\section{RESULTS}

\subsection{Socio-Demographic Characteristics of Survey Respondents}

EMIC interview participants were made up of 30 males and 31 females with the mean $( \pm$ Std) age of 39.6 years. Majority of the survey respondents were Muslim (73.8\%) and most of them were married (67.2\%). Majority (67.2\%) of them had no education and were mainly farmers (70.5\%) and petty traders (16.4\%).

\subsection{Common Illnesses}

Malaria/fever (98.4\%) was the most common illness mentioned by respondents. The rest were coughing (62.3\%), stomach pains (54.1\%), diarrhoea (26.2\%) and chest pains (21.3\%). However, among all these health problems the two most troubling reported were malaria/fever (45.9\%) and coughing (22.9\%). Almost all (95.1\%) survey respondents said persistent cough or suspected TB was a problem in the district. The most prominent local name/term for TB reported was Kesibine (85.2\%). Kesibine was also mentioned as the local name for TB during in-depth interview with traditional healers and community leaders as well as during focus group discussion (FGD) with the general adult population. All related names/terms for TB have meanings attached to them, for example, the term Kesibine or kesibelle was explained to mean "black cough or prolong cough with blood in the sputum", the term Boye was explained to mean "coughing with blood" and Kukuezine means "coughing till blood comes out".

\subsection{Distresses Suffered by Suspected TB Patients}

Various distresses associated with TB were reported by suspected TB patients, prominent distress reported spontaneously was reduced income $(60.7 \%)$ while the two most frequently reported distresses after probing were coughing (96.7\%) and chest pains (95.0\%) (Table 1)

Table 1. Distresses reported either spontaneously or probed*.

\begin{tabular}{|c|c|c|c|c|}
\hline \multirow{2}{*}{ Constraining Factors (Variables) ${ }^{* *}$} & Spontaneous Responses & \multicolumn{2}{|c|}{ Probed Responses } & \multirow{2}{*}{$\begin{array}{r}\text { Total } \\
\%\end{array}$} \\
\hline & Frequency & Frequency & $(\%)$ & \\
\hline Blood in sputum & $10(16.4)$ & \multicolumn{2}{|c|}{$22(36.1)$} & 52.5 \\
\hline Breathlessness & $18(29.5)$ & \multicolumn{2}{|c|}{$30(49.2)$} & 78.7 \\
\hline Chest pains & $7(11.4)$ & \multicolumn{2}{|c|}{$51(83.6)$} & 95.0 \\
\hline Concern about course of illness & $25(41.0)$ & \multicolumn{2}{|c|}{7 (11.5) } & 52.5 \\
\hline Difficulty finding partner & $14(23.0)$ & \multicolumn{2}{|c|}{$11(18.0)$} & 41.0 \\
\hline Fever & $16(26.2)$ & \multicolumn{2}{|c|}{$25(41.0)$} & 67.2 \\
\hline Headache & $23(37.7)$ & \multicolumn{2}{|c|}{$27(44.3)$} & 82.0 \\
\hline Loss of appetite & $13(21.3)$ & \multicolumn{2}{|c|}{$18(29.5)$} & 50.8 \\
\hline Loss of job/wage & $19(31.1)$ & \multicolumn{2}{|c|}{$1(1.6)$} & 32.7 \\
\hline Marital Problems & $11(18.0)$ & \multicolumn{2}{|c|}{$13(21.3)$} & 39.3 \\
\hline Reduced social status & $15(24.6)$ & \multicolumn{2}{|c|}{$14(23.0)$} & 47.6 \\
\hline Sadness, anxiety or worry & $35(57.4)$ & \multicolumn{2}{|c|}{$14(23.0)$} & 80.4 \\
\hline Side effect of drugs & 18 (29.5) & \multicolumn{2}{|c|}{$1(1.6)$} & 31.1 \\
\hline Social isolation & $18(29.5)$ & \multicolumn{2}{|c|}{$11(18.0)$} & 47.5 \\
\hline Weakness & & 27( & & 83.6 \\
\hline Weight loss & & 31( & & 78.7 \\
\hline
\end{tabular}

*Multiple choices allowed; ${ }^{* *}$ Sorted alphabetically in column 1. 
The following representative narratives confirmed the importance of the distresses reported:

$T B$ may lead to reduction in the income of the patient and this in itself can lead to death. ...affects both the economic and physical live of the patients which make them feel miserable (Male traditional healer, IDI).

...TB in the family can disturb other family members as they waste a lot of money and time on the patient. In this community TB patients are not allowed to have sex with their husbands and this make life difficult for the family and in some cases the man will go and marry another wife while keeping the original wife in isolation (female traditional healer, IDI).

Majority of the survey respondents (80.3\%) maintained that women who have TB suffer from it more than men in the district for various reasons, some of which were represented in the following narratives:

There are some differences...the truth is that women with suspected TB find it more difficult to live with the disease. ... a woman with TB will never get a partner to marry in this community, but a man with TB can easily get a partner to marry (Female, FGD).

...people relate to male and female patients differently...a man with suspected TB is never suspected of having AIDS but every woman with suspected TB is taken to be AIDS patient and this makes life very difficult we the women (Female suspected patient, EMIC interview).

\subsection{Causes of TB}

Varied causes of TB were reported and the most prominent cause reported was sexual pollution (72.2\%). Thus, spontaneously (45.9\%) and after probing (26.3\%) (Table 2). The following representative narratives explained some of the causes in detailed:

Kessibine (TB) is transmitted through sexual intercourse with an infected person. ...drinking fresh milk from infected animals could also cause it (male opinion leader, IDI).

The disease is transmitted through exchange of saliva with an infected person. ...when shared a handkerchief with infected persons and through sexual intercourse, especially when the woman coughs during sex (female, FGD).

When you sleep with a woman and she carelessly cough on you, you could develop TB. You can also get TB from eating cat meat or other infected animas. It is in the air but it can also be caused when one partner during sexual intercourse cough very deeply. It can also be caused by over working and drinking of bad water (Male traditional Healer, IDI).

Table 2. Perceived causes reported either spontaneously or after probing*

\begin{tabular}{|c|c|c|c|}
\hline \multirow{2}{*}{ Perceived Causes (Variables) ${ }^{* *}$} & Spontaneous Responses & Probed Responses & \multirow{2}{*}{ Total \% } \\
\hline & Frequency & Percentage & \\
\hline Drugs abused & $6(9.8)$ & $12(19.7)$ & 29.5 \\
\hline Air borne/exposure & $16(26.2)$ & $23(36.1)$ & 62.3 \\
\hline Alcohol & $12(19.7)$ & $16(26.2)$ & 45.9 \\
\hline Blood-related problems & $18(29.5)$ & $13(21.3)$ & 50.8 \\
\hline Constitutional weakness & $13(21.3)$ & $4(6.6)$ & 27.9 \\
\hline Contact with Affected Person & $14(23.0)$ & $11(18.0)$ & 41.0 \\
\hline Evil spirits/gods & $15(24.6)$ & $6(9.8)$ & 34.4 \\
\hline Fate (star) & $14(23.0)$ & $4(6.6)$ & 39.6 \\
\hline Food & $8(13.1)$ & $17(27.9)$ & 41.0 \\
\hline Germs/infections & 7 (11.5) & $11(18.0)$ & 29.5 \\
\hline Hereditary & 7 (11.5) & $12(19.7)$ & 31.2 \\
\hline Insect bite & $6(9.8)$ & $16(26.2)$ & 36.0 \\
\hline Lack of personal hygiene & $10(16.4)$ & $5(8.2)$ & 24.6 \\
\hline Lack of sanitation & $11(18.0)$ & $9(14.8)$ & 32.8 \\
\hline Mental/emotional stress & $11(18.0)$ & $6(9.8)$ & 27.8 \\
\hline Neglected previous illness & $12(19.7)$ & $3(4.9)$ & 24.6 \\
\hline Physical exertion/hard work & $8(13.1)$ & $21(34.4)$ & 47.5 \\
\hline Pregnancy/child birth & $17(27.9)$ & 0 & 27.9 \\
\hline Prescribed medicines & $8(13.1)$ & $10(16.4)$ & 29.5 \\
\hline Previous illness & $16(26.2)$ & $4(6.6)$ & 32.8 \\
\hline Sexual pollution & $28(45.9)$ & $16(26.3)$ & 72.2 \\
\hline Smoking & $14(23.0)$ & $22(36.1)$ & 59.1 \\
\hline Water & $6(9.8)$ & $18(29.5)$ & 39.3 \\
\hline
\end{tabular}

*Multiple choices allowed; ${ }^{* *}$ Sorted alphabetically in column 6. 


\subsection{Traditional Healers and TB Treatment}

Five out of the six traditional healers interviewed said that they are able to treat and cure TB completely. They however admitted that, just like biomedicine, some suspected TB patients who came to them did not receive complete cure. They were of the view that some of the patients require being on treatment for very long time in order to get cured, which was not affordable to the patients both in terms of time and money. The following narratives vividly captured these positions:

In some TB cases, our herbal medications are more effective and better than biomedicines. ...they are sometimes treated badly at the hospital...they prefer coming to us ...so instead of condemning us, we should be supported to help treat TB patients (Male Traditional healer, IDI).

\subsection{Health Seeking for Suspected TB}

Most of the survey respondents (85.2\%) sought help when they suspected that they have TB and they reportedly went to the Government hospital/clinics (84.6\%). However, they maintained that no sputum sample was taken from them for laboratory analysis, even though they had reported that they were coughing for more than two weeks. Also, all survey respondents admitted that they had consulted traditional healers at one time or the other for their prolong coughing. The following narratives vividly echoed that position:

I went to the clinic at the beginning of my problem, but I must say that the way suspected TB patients are treated in this community makes it difficult for me to keep going to the clinic to avoid being labelled as an IDS patient (Middle aged lady, FGD).

Health workers interviewed were of the view that TB patients have lukewarm attitude towards treatment as indicated in the following representative narratives:

During intensive treatment period, they (patients) usually complain about the injections or drugs as being too much (A Nurse at the District Hospital).

Patients that were diagnosed in the past did not come to the clinic regularly to collect or take their medications and this affected the progress of the programme (District TB focal person).

Majority of respondents (91.8\%) said they will support the idea of community DOT provided the "providers" are trained community members who they can trust. They maintained that they will readily utilise the services of the community DOT providers but will be happy if they would come to their homes with the medicines.

\subsection{Stigma}

Majority (63.9\%) of the survey respondents said they have never tried to prevent other people from knowing about their persistent cough (suspected TB). However, $29.5 \%$ of them said they have tried to hide their condition from other people. Also, majority (75.4\%) of them have discussed their condition with persons they considered intimate. For those who discussed their problem with close relatives, most of them talked to either their spouse $(47.8 \%)$ or parents (37.0\%). The following narratives explained why some respondents will not want to talk about their condition to others:

...TB is viewed in this community as a bad and dangerous disease, so if you have it, people will not want to associate with you, they will not want to eat with you and this makes you feel uncomfortable (lady FGD).

Those with $T B$ will not declare it publicly because people in this community see TB patients as corps (living but dead, they are not even allowed to have sex with their partners (male FGD).

The following narratives revealed how community members will relate to their spouses when they are diagnosed with TB;

I will not eat with her or eat any leftover from her plate (male local healer, IDI).

...not have sex with her and I will not share a drinking cup with her, though I will support her to attend clinic for treatment (male FGD).

...will relate nicely to him but I will not eat with him because it is not good to get too closer to him (female FGD).

About halve of the survey respondents (50.8\%) said they think less of themselves because of their persistent coughing. Also, majority (52.5\%) said they were sometimes made to feel shame because of their condition. Moreover, $54.1 \%$ of them said they were less respected in the district because of their condition. The following narratives explained these positions;

In this community, once people know that you have TB, they will not want to have anything to do with you. They will start to look at you as a good for nothing person who is awaiting death; they will be careful not to contract the disease (lady suspected TB patient, EMIC).

Some people will be sympathetic with you and try to help you but others will think less of you because they will continue to think that you got the disease through sexual pollution (lady suspected TB patient, EMIC).

About halve (49.2\%) of the survey respondents said that they never suspected that people were trying to avoid them. However, 26.2\% reported that people have tried to avoid them because of their conditions while 21.3\% were not sure. On the other hand, health workers interviewed reported that patients who came to them in the past were worried that others would get to know about their TB status. These patients were then assured of confidentiality of their clinical records. Health workers also maintain that the fear of stigmatisation may be 
the cause of low TB case reporting to the health facility for diagnosis and treatment. These positions were aptly explained in the following narrative:

People always think that if you have TB it means that you have carelessly coughed during sexual intercourse and therefore shun your company and this have negatively affected the confidence of suspected TB patients to come to the clinic for fear that they will be exposed to public ridicule (Nurse, IDI).

\subsection{Defaulter Rate}

Treatment default rate was reportedly high as captured in the following narratives:

Some people do stop going for their medications because they do not want others to find out that they have $T B$...some do not start at all...in my case, I am planning to go but I am yet to discuss it with my husband (Female suspected patient, EMIC).

We have seen only a few cases here and once they are getting better or saw some improvement in their health, they stop coming for medications (Nurse, IDI).

People stop coming for TB medication because of their preference for traditional healers and self medications as a way of keeping other people away from knowing about their TB status. Some people do complain about the side effects of the medication and I think that may be one of the reasons why they default on treatment (District $\mathrm{TB}$ focal person, IDI).

...Dropping out of treatment do not happened only with the orthodox medication but also with our herbal medication too. ...the reason is that when the patients are treated for some time, their condition improves then they think that they are cured. ...some people naturally do not like taking medicine and have to be forced to take it. For such people, once their condition gets better they will definitely stop coming for the medication (Male Traditional Healer, IDI).

\subsection{Reasons for Not Attending clinic/Hospital with TB}

Formal health workers interviewed reported that suspected TB cases were going to traditional healers instead of the clinic/hospital because of the persistent belief that TB is caused by witches. This was represented in the following narrative:

Our culture made people to think that TB is caused by witchcraft or other malevolent spirits; hence their preference for traditional healing practices (Hospital Laboratory Technician, IDI).

I think that religious believes are also affecting the rate at which suspected TB patients come to the clinic because they sometimes believe that TB can be cured through prayers from Muslim healers (Malams) (Com- munity health nurse, IDI).

\subsection{Case Detection and Treatment}

Case detection and treatment is hampered by the fact that there is no facility at the sub-district levels for testing suspected patients. Also, drugs are received from the district level only when a case has been confirmed at the District hospital. Staff at the sub-district level have lamented that most specimen sent to the district hospital for testing either have no results send to them or takes so long before the result are sent to them and this was putting probable patients way from reporting at their facilities. They maintained that, it was making things difficult for them, especially when they do not know what to do for the patients without the test result. The following narratives captured in detail the difficulty that periphery facilities go through to diagnose and treat TB.

In fact there are many problems with the way we treat suspected TB cases here. In the first place the people are unwilling to come because of stigmatisation but the few that come to us also have to wait for a long time before getting into treatment because we have to wait for the test result from Tumu. You see this young girl (pointing to the girl); it took more than one year to get her into treatment because we did not get the laboratory result from Tumu. ...the patient kept coming to me ...I sent another sample and this time, nothing was heard from Tumu about it. ...about three month ago I sent a third sample ...I followed it up on every market day until about two weeks ago when I received the test result and it was positive. ...she is now on drug and looking a bit better now. How can you explain this situation to suspected TB patients? (A nurse: in charge of a sub-district facility, IDI).

\subsection{Financial and Social Support}

Majority (70.5\%) of the survey respondents said they were being supported by their spouse and other family members in various ways, especially financial and social supports (Table 3). The three most important decision makers during illness in the Sissala East Districts were parents (54.1\%), the sick person himself (27.9\%) and spouse (21.3\%).

\section{DISCUSSION}

The results show that people with suspected cough and other community members as well as traditional healers were aware that TB could be treated at biomedical health facilities. However, people who have coughed for more than 14 days (suspected TB cases) were not going to the health facilities for diagnosis and treatment $([6,7,10]$, gmj 2008, phm 2009). Various reasons could be assigned to this behaviour; however from our results three main 
Table 3. Sources of financial support available to suspected TB patients.

\begin{tabular}{ccc}
\hline $\begin{array}{c}\text { Variable } \\
\text { (Sources of Financial Support) }^{\text {Parents }}\end{array}$ & Frequency $^{* *}$ & Percentage \\
\hline Self & 41 & 67.2 \\
Spouse & 24 & 39.3 \\
Adult children & 15 & 24.6 \\
Extended family members & 14 & 23.0 \\
Friends & 12 & 19.7 \\
Religious affiliations & 4 & 6.6 \\
\hline
\end{tabular}

*Multiple choices allowed; ${ }^{* *}$ Sorted in descending order in column 2.

reasons clearly stood out. The first one was the fear of stigmatization both by community members and health care providers. Community members presumed every suspected TB patient to be suffering from HIV/AIDS, a condition that is even more stigmatized than TB in the study area ([16], Weiss 2006) and similar findings were reported from elsewhere [12,13] It is good for health care providers to protect themselves against infections but when this is done in ways that cause some discomfort to patients then it may serve as a disincentive for seeking health at health facilities ([13-15], gmj 2008, phm 2009).

Secondly, the lack of effective communication between the peripheral facilities and the laboratory at the district hospital, where the results for samples from the periphery facilities are not communicated on time and in some cases not communicated at all, could also be affecting the confidence of suspected patients in the health care facilities since the laboratory results are needed for the initiation of treatment or otherwise. This may also affect health care providers at the periphery facilities as they may not be encouraged to send more samples to the district laboratory.

Thirdly, the availability of traditional healers to manage suspected TB cases either rightly or wrongly may be keeping suspected patients away from the health care facilities because they share a common worldview and local beliefs with suspected patients, which makes them more attractive ([6,10], Dodor 2008).

While the men reported that there was no gender differences in the distresses suffered by TB patients; most of the ladies, especially during FGD sessions, said there were some gender differences in TB-related distresses in the community. These differences must therefore be taken seriously and dealt with when working on TB stigma reduction in the district. This findings show how quantitative data alone could not clearly bring out the features of stigma and other distresses associated with $\mathrm{TB}$, especially among women in a male dominated envi- ronments.

Both health care providers and healers complained of high treatment dropout among TB patients. This must be addressed through patients' education and support system. The need and importance of completing treatment to reduce the risk of the emergence of drug resistance must be emphasized ([6,10], Dodor, 2008, gmj 2008, phm 2009). The dangers and benefits associated with treatment dropout must be drummed home in ant TB-related health education programme in the study area.

The introduction of community-based DOT for TB treatment was endorsed by respondents. However, this must be implemented by training volunteers sufficiently enough not only to deliver and supervise medication but also to identify suspected cases and support them to report at designated health care facilities. This may be useful considering the distance some patients have to cover to access health services as this will reduce the travel cost to the patients and family caretakers and thereby improve treatment adherence [1].

TB patients, apart from the stigma also suffer from lack of income due to reduce capacity to work. TB also damage intimate relationships since women with suspected TB were not allowed to have sex with their husbands and this could lead to divorce and neglect which will further exacerbate the suffering of the patient $[6,10]$.

\section{CONCLUSIONS}

The understanding of TB as a deadly disease should serve as an entry point to encourage appropriate health seeking behaviour for suspected TB patients. To be successful, however there is the need to emphasise the point that TB could become deadly only if it is not treated at the clinic/hospital appropriately early. Also, the availability of effective treatment at health facilities must be promoted. The need to expand laboratory facilities to the periphery facilities could not be overemphasized as this greatly affects the time of first health seeking for suspected TB and the start of the actual treatment. The situations where laboratory results take months to be made available to the periphery facilities cannot be allowed to persist if the current control measures are to make headway as expected.

Although this study did not verify the claim by traditional healers that they could cure TB, the control programme should find a collaborative way to use healers to gain access to suspected TB patients. This is because the people will continue to visit traditional healers as the local perception of TB naturally favours the use of the services of traditional healers. There is therefore the need for vigorous health education to inform the people about the biomedical causes of TB and the availability of appropriate treatment for the disease at health facilities. However, the education should not aim at changing the 
"wrong beliefs" but focus on making people aware of the biomedical causes and see TB as treatable infection, which could be controlled.

\section{ACKNOWLEDGEMENTS}

We are grateful to the Sissala East District Health Administration for collaborating with us on this study. We sincerely thank the community assistants and the two research assistants who conducted the interviews and performed translation during qualitative data collection for their assistance on the field. Thanks to professor Koram for his support and Cynthia Ahorlu for data entry and secretarial support. Many thanks to the chiefs and people of the study area especially the respondents. Financial support was provided by the Ghana National TB Control Programme, Ghana Health Service, Accra.

\section{REFERENCES}

[1] World Health Organization (2011) ChouWHO report. Global TB control. WHO/ HTM/TB/2011.16. WHO, Geneva, Switzerland.

[2] Hargreaves, J.R., Boccia, D., Evans, C.A., Adato, M., Petticrew, M. and Porter, D.H. (2010) The social determinants of Tuberculosis: From evidence to action. American Journal of Public Health, 101, 654-662. http://dx.doi.org/10.2105/AJPH.2010.199505

[3] World Health Organization (2010) WHO report 2010. Global TB control. WHO/HTM/TB/2010.7. WHO, Geneva.

[4] Balasubramanian, V.N., Oommen, K. and Samuel, R. (2000) Dot or not? Direct observation of anti tuberculosis treatment and patient outcomes, Kerala State, India. The International Journal of Tuberculosis and Lung Disease, 4, 409-413.

[5] Gilani, S.I. and Khurram, M. (2012) Perception of tuberculosis in Pakistan: Findings of a nation-wide survey. Japan Pharmaceutical Manufacturers Association, 62, 116-120.

[6] Lawn, S.D. and Achempong, J.V.V. (1999) Pulmonary tuberculosis in adults: Factors associated with mortality at a Ghanaian teaching hospital. West African Journal of Medicine, 18, 270-274.

[7] (2006) Technical policy and guidelines for TB/HIV collaboration in Ghana. Ghana Health Service, Accra.

[8] Dodor, E.A. and Afenyadu, G.Y. (2005) Factors associated with tuberculosis treatment default and completion at the Effia-Nkwanta Regional Hospital in Ghana. Transactions of the Royal Society of Tropical Medicine and Hygiene, 99, 827-832.

http://dx.doi.org/10.1016/j.trstmh.2005.06.011

[9] Lawn, S.D. (2000) Tuberculosis in Ghana: Social stigma and compliance with treatment. International Journal of Tuberculosis and Lung Disease, 4, 1190-1191.
[10] Dodor, E.A. (2008) Health professionals expose TB patients to stigmatization in society: Insights from communities in an urban District in Ghana. Ghana Medical Journal, 42, 144-148.

[11] Doror, E.A., Kelly, S. and Neal, K. (2009) Health professionals as stigmatizers of tuberculosis: Insights from community members and patients with TB in an urban district in Ghana. Psychology, Health \& Medicine, 14, 301-310. http://dx.doi.org/10.1080/13548500902730127

[12] Data, K., Bhatnagar, T. and Murhekar, M. (2010) Private practitioners' knowledge, attitude and practices about TB, Hooghly district, India. Indian Journal of Tuberculosis, 57, 199-206.

[13] Goffman, E. (1963) Stigma: Notes on the management of spoiled identity. Prentice Hall, Englewood Cliffs.

[14] Weiss, M.G., Ramakrishna, J. and Somma, D. (2006) Health-related stigma: Rethinking concepts and interventions. Psychology, Health \& Medicine, 11, 277-287. http://dx.doi.org/10.1080/13548500600595053

[15] Lawn, S.D., Afful, B. and Acheampong, J.W. (1998) Pulmonary tuberculosis: Diagnostic delay in Ghanaian adults. International Journal of Tuberculosis and Lung Disease, 2, 635-640.

[16] Hancock, C. and Oulton, J.A. (2003) Nurses: Fighting AIDS stigma, caring for all. International Council of Nurses, Geneva.

[17] Liefooghe, R., Michiels, N., Habib, S., Moran, M.B. and De Muynck, A. (1995) Perception and social consequences of tuberculosis: A focus group study of tuberculosis patients in Sialkot, Pakistan. Social Science \& Medicine, 41, 1685-1692. http://dx.doi.org/10.1016/0277-9536(95)00129-U

[18] Macq, J., Solis, A., Martinez, G., Martinez, P. and Dujardin, B. (2005) An exploration of the social stigma of tuberculosis in five "municipios" of Nicaragua to reflect on local interventions. Health Policy, 74, 205-217. http://dx.doi.org/10.1016/j.healthpol.2005.01.003

[19] Volinn, I.J. (1983) Health Professionals as stigmatizers and destigmatizers of diseases: Alcoholism and leprosy as examples. Social Science \& Medicine, 17, 385-393. http://dx.doi.org/10.1016/0277-9536(83)90341-6

[20] Rafferty, J. (2005) Curing the stigma of leprosy. Leprosy Review, 76, 119-126.

[21] Yeboah-Manu, D., Asante-Poku, A., Ampah, K.A., Kpeli, G., Danso, E., et al. (2012) Drug susceptibility pattern of mycobacterium tuberculosis isolates from Ghana; correlation with clinical response. Mycobacterial Disease, 2, 107. http://dx.doi.org/10.4172/2161-1068.1000107

[22] Weiss, M.G. (2001) Cultural epidemiology: An introduction and overview. Anthropology \& Medicine, 8, 5-29. http://dx.doi.org/10.1080/13648470120070980

[23] (2012) Population and Housing census. Summary of final results. Ghana Statistical Service, Accra. 